Patrick Sharp*, DO, Jaclyn Slattery, DO, Austin Johnson, BS, Trevor Torgerson, BS, Ryan Ottwell, DO, Matt Vassar, PhD and Micah Hartwell, PhD

\title{
The use of person-first language in scientific literature focused on drug-seeking behavior: a cross-sectional analysis
}

https://doi.org/10.1515/jom-2021-0149

Received May 11, 2021; accepted July 13, 2021;

published online August 24, 2021

\section{Abstract}

Context: Person first language (PFL) - a way of referring to individuals with medical conditions or disability that emphasizes the person over their condition or disability - is important in reducing the stigma surrounding individuals who exhibit drug-seeking behavior. Drug-seeking behavior is generally associated with a negative connotation by healthcare professionals, which may create poor provider perceptions of these individuals and potentially impact patient care. Therefore, to reduce stigmatization surrounding drug-seeking behavior and to improve patient care in these individuals, the use of PFL should be promoted.

Objectives: The primary objective of this study is to investigate how frequently research articles focused on drug-seeking behavior adhere to PFL.

Methods: We performed a cross-sectional analysis systematically searching PubMed for articles published between May 1, 2011, and April 30, 2020, focused on drugseeking behavior. To be included, the article must have met the following criteria: (1) published in a peer-reviewed journal; (2) relevant to drug-seeking behavior; and (3) must include human subjects and be retrievable in English. All articles were screened and data were extracted independently in a masked, duplicate fashion. Each article was reviewed for 19 predefined non-PFL terms with certain terms adopted from the American Medical Association Manual of Style.

\footnotetext{
*Corresponding author: Patrick Sharp, DO, Oklahoma State University Center for Health Sciences, 1111 W 17th Street, Tulsa, OK 74107, USA, E-mail: pdubsharp@gmail.com Jaclyn Slattery, DO, Austin Johnson, BS, Trevor Torgerson, BS, Ryan Ottwell, DO, Matt Vassar, PhD and Micah Hartwell, PhD, Oklahoma State University Center for Health Sciences, College of Osteopathic Medicine, Tulsa, OK, USA
}

Results: Our search returned 699 articles related to drugseeking behavior, of which 390 articles met inclusion criteria and were analyzed for non-PFL. Our analysis found only $13.6 \%$ (53/390) of articles adhered to PFL while $86.4 \%$ (337/390) of articles contained at least some form of nonPFL. There was no association between PFL adherence and extracted study characteristics.

Conclusions: PFL adherence is uncommon among research literature focused on drug-seeking behavior. The power of language can be profound, and should be understood by researchers, health care providers, and educators alike, specifically when dealing with known and exhibited characteristics of substance use disorders. This is relevant because of the high prevalence of substance use disorders, limited amount of prior research, and the impact stigma has on patients and healthcare providers.

Keywords: drug-seeking behavior; medical literature; person-first language.

In 2017, an estimated 18 million people incorrectly used prescription medications at least once [1], and nearly 42,000 deaths were linked to opioid-misuse alone [2, 3]. One study estimated that in an emergency department with 75,000 annual visits, 262 visits per month were related to patients with drug-seeking behavior [4]. Perceptions of drug-seeking behavior may perpetuate negative stereotypes of individuals with substance use disorders [5]. These perceptions are generally associated with a negative connotation by physicians and medical staff and thus may create poor provider perceptions of these individuals $[4,6]$. To ensure that people aren't defined or labeled as a singular aspect of their condition, the patient-centered care model applies the use of person-first language (PFL) - a way of referring to individuals with medical conditions or disability that emphasizes the person over their condition or disability [7] - which acknowledges the whole person, and thus humanizes the individual and reduces stigma [8]. 
Using PFL is critically important in medical literature, as the research that defines medical practice is taught in medical education, which is then translated into clinical practice [7, 8]. Advocacy for PFL has begun. Some journal editorial boards go out of their way to request language used in submissions be careful and intentional, and others have gone as far to publish examples of unacceptable words with their alternatives [9-11]. This translation of stigmatizing language into clinical practice may create barriers between patients and providers, which is deleterious towards any group of people in patient care [12]. In general, health professionals have been found to have a negative attitude towards patients with substance use disorders [5]. For example, Biancarelli et al. [13] found that participants who used intravenous drugs anticipated stigma from health professionals when seeking treatment and reported they were treated unfairly or discriminated against because of their injection drug use. The expected stigmatization among these patients resulted in delay of treatment, delay in drug use reporting, and ultimately resulted in seeking healthcare elsewhere [13].

In an attempt to increase the use of PFL, multiple groups have adopted guidelines for its adherence, such as the American Psychological Association [14], the American Psychiatric Association [15], and the American Medical Association (which publishes the American Medical Association's Manual of Style [AMAMS]) [16], the latter of whom incorporated it in 2007 [17-19]. Likewise, the International Committee of Medical Journal Editors (ICMJE) also calls for respectful and non-stigmatizing language [20]. However, whether or not these guidelines are followed in relation to individuals exhibiting drug-seeking behaviors has yet to be investigated. Thus, our primary objective is to investigate how frequently research articles adhere to PFL and avoid stigmatizing language. Additionally, we further evaluate particular study characteristics to identify associations related to the use of PFL.

\section{Methods}

\section{Article selection and inclusion criteria}

To evaluate the current use of PFL we performed a cross-sectional analysis systematically searching PubMed on April 30, 2020. We used a previously developed search string to search for articles related to drug-seeking behavior [21]. The PubMed search string can be found in Table 1. Retrieved articles were then screened for inclusion criteria, which consisted of the following: the article must have been (1) published in a peer-reviewed journal; (2) relevant to drug-seeking behavior; (3) published between May 1, 2011, and April 30, 2020;
Table 1: Search string used for retrieval of articles.
PubMed search:
(1) Overlapping prescriptions [Text word]
(2) Doctor shopping [Text word]
(3) Doctor-shopper [Text word]
(4) Physician shopping [Text word]
(5) Physician-shopper [ Text word]
(6) Double doctoring [Text word]
(7) Double doctoring [Text word]
(8) (Doctor) AND switch*
(9) (Physician) AND switch*
(10) \#1 OR \#2 OR \#3 OR \#4 OR \#5 OR \#6 OR \#7 OR \#8 OR \#9

and (4) and must include human subjects and be available in English. For the purposes of this study, we excluded articles related to alcohol and nicotine addiction as the substances are not regulated by the Controlled Substances Act [22], and while procurement of these substances by dishonest means occurs, the settings (e.g., stores, residences) are outside of the medical realm (e.g., hospitals, pharmacies). Our investigation was not subject to institutional review board oversight as outlined by the US Department of Health and Human Services' Code of Federal Regulations [23].

\section{PFL and data extraction}

Prior to article screening and data extraction, investigators completed two days of training in strictly defining PFL using the definitions provided by SAMHSA's Substance Use Disorders: A Guide to the Use of Language [24] and the AMAMS, 11th edition [19] and identifying the presence of non-PFL terms (non-PFL words and phrases were adapted from both sources). Investigators (P.S. and J.S.) searched 30 random articles in our sample to find additional non-PFL examples not identified in the AMAMS [19] or SAMHSA's Substance Use Disorders: A Guide to the Use of Language [24]. The following non-PFL terms and phrases were extracted from each article: "addict," "user," "drug user," "abuser," "substance user," "drug seeker," "frequent flyer," "drug abuser," "substance abuser," "benzodiazepine abuser," "opioid abuser," "doctor shopper," "pill popper," "doper," "pseudoaddict," "sufferer," "suffers from," "afflicted with," and "problematic/problem with". The singular and plural use of each word was accepted. The context of the word use was evaluated. For example, if an article condemed the use of a searched term or the term was quoted, that usage was not counted.

The following characteristics were also extracted: article type (original article, editorial, case report), the type of research performed (literature review, cross-sectional/observational, meta-analysis/systematic review, clinical trials), type of intervention, the publishing journal's impact factor, type of journal (coded as addiction specialty, general, or other specialty including pain, psychiatry, neurology, and pharmacology), whether the article mentioned adhering to reporting guidelines (e.g., PRISMA, CONSORT, or STROBE), and whether the publishing journal recommends adherence to AMAMS or ICMJE. Data were extracted independently in a masked, duplicate fashion by two investigators (P.S. and J.S.). Following extraction, the investigators were unmasked and reconciled disagreements. 
Systematic Search: A systematic search of PubMed articles focused on individuals and patients exhibiting drug-seeking behavior was conducted on 5/7/2020 spanning May 1, 2011 to April 30, 2020.

\section{Search Returns:}

699 results from 314 journals.

Article Eligibility: All peer-reviewed original research articles, including research letters, brief reports, and case reports (including published poster presentations and abstracts), and editorials covering drug-seeking behaviors were retained.

\begin{tabular}{|c|c|}
\hline covering drug-seeking behaviors were retained. & \multirow{3}{*}{$\begin{array}{l}\text { Articles Retained: } 390 \text { articles from } 189 \text { journals } \\
\text { met inclusion criteria. Excluded articles did not } \\
\text { cover drug-seeking behavior (254), were not in } \\
\text { peer-reviewed journals or were comments (39), } \\
\text { were animals studies (11), were not published in } \\
\text { English (4), or duplicated (1). }\end{array}$} \\
\hline & \\
\hline \multirow{2}{*}{$\begin{array}{l}\text { Data Extraction for Primary Objective: Primary Objective: } \\
\text { Articles were systematically search for non-PFL terms, identified a } \\
\text { priori, to evaluate article adherence to AMAMS guidelines. Terms/ } \\
\text { Phrases included: "overlapping prescriptions", "doctor shop", } \\
\text { "physician shop"", "double doctor"", "drug seek"", "doctor } \\
\text { switch"", "physician switch" ", "opioid seek" }\end{array}$} & \\
\hline & \multirow{2}{*}{$\begin{array}{l}\text { Primary Outcome: Of the } 390 \text { articles, } 53 \\
\text { (13.5\%) articles adhered to PFL according to } \\
\text { AMAMS guidelines. }\end{array}$} \\
\hline$\sqrt{7}$ & \\
\hline \multirow[t]{2}{*}{$\begin{array}{l}\text { Data Extraction for Secondary Objective: Secondary Objective: } \\
\text { Study characteristics extracted from articles to assess their } \\
\text { association with PFL including type of article, type of study, } \\
\text { reporting guidelines, funding source and journal impact factor. }\end{array}$} & \\
\hline & Secondary Outcomes: Adherence to PFL did not \\
\hline & $\begin{array}{l}\text { types, research funding, journal requirements for } \\
\text { adherence to AMA and ICMJE guidelines, or } \\
\text { journal impact factor (Table 1). }\end{array}$ \\
\hline
\end{tabular}

Figure 1: Flow chart of systematic investigation and outcomes of PFL in accepted manuscripts focused on persons exhibiting drug seeking behavior.

\section{Data analysis}

Frequencies and percentages were calculated for the number of articles that were PFL adherent according to the AMAMS guidelines from the overall sample and by year (2011-2019). Additionally, we tallied the number of times non-PFL were present within the articles. Fisher's exact tests were used to determine associations between study characteristics and a binary variable of whether the journal requires adherence to AMA or ICMJE guidelines. Logistic regression determined the degree of association between journal impact factor and PFL adherence. Analysis was done using STATA 16.1 (StataCorp, College Station, TX) and conformed to STROBE reporting guidelines [23].

\section{Results}

Our search returned 699 articles from 314 different journals. After screening for inclusion criteria, our final sample included 390 articles related to drug-seeking behavior from 189 journals (Figure 1). Of the articles, 84 (of 390, 21.5\%) were published in general medical journals, and 48 (of 390, 12.3\%) were from the addiction specialty, while most of the articles $(258 / 390,66.2 \%)$ were published in specialty journals including pharmacology, psychiatry, and neurology (Table 2). Only 137 articles $(137 / 390,35.1 \%)$ were published in journals that required adherence to either AMAMS or ICMJE. Journal impact factors ranged from 0.07 to 41.06 (mean, 4.77; standard deviation, 4.87). When comparing article types, editorial studies adhered to PFL more often (32/183, 17.5\%).

In total, we found 669 uses of non-PFL in the 390 sampled articles, of which the three most commonly identified non-PFL uses were "user" (218/669, 32.6\%), “addict” (128/669, 19.1\%), and "abuser" (107/669, 16\%). Within the searched timeframe, 2014 had the most articles focused on drug-seeking behavior (Figure 2) and the most non-PFL occurrences in our sample (124/669, 18.5\%; Table 3); however, regression analysis showed a non-statistically significant change over time $(t=-1.41$, $\mathrm{p}=0.20$ ). We found no statistical difference between PFL 
Table 2: General characteristics of included articles and frequencies of articles adherent to PFL.

\begin{tabular}{|c|c|c|c|c|}
\hline \multirow{2}{*}{$\begin{array}{l}\text { Article } \\
\text { characteristic }\end{array}$} & \multicolumn{4}{|c|}{ No. $(\%)$ of articles $(n=390)$} \\
\hline & $\begin{array}{r}\text { Total, } \\
\%\end{array}$ & $\begin{array}{r}\text { Articles not } \\
\text { adhering to } \\
\text { PCL }\end{array}$ & $\begin{array}{r}\text { Articles } \\
\text { adherent to } \\
\text { PCL }\end{array}$ & $\begin{array}{r}\text { p- } \\
\text { Value }\end{array}$ \\
\hline \multicolumn{5}{|l|}{ Types of journal } \\
\hline Addiction & 48 & 41 & 7 & 0.69 \\
\hline Other specialty & 258 & 221 & 37 & \\
\hline General medicine & 84 & 75 & 9 & \\
\hline \multicolumn{5}{|l|}{ Types of article } \\
\hline Case report & 5 & 4 & 1 & 0.12 \\
\hline Editorial & 183 & 151 & 32 & \\
\hline Original research & 200 & 180 & 20 & \\
\hline Other & 2 & 2 & 0 & \\
\hline \multicolumn{5}{|l|}{ Type of research } \\
\hline Clinical trial & 57 & 50 & 7 & 0.46 \\
\hline Literature review & 177 & 148 & 29 & \\
\hline $\begin{array}{l}\text { Observational/ } \\
\text { cross-sectional }\end{array}$ & 29 & 108 & 12 & \\
\hline $\begin{array}{l}\text { Systematic review/ } \\
\text { meta-analysis }\end{array}$ & 120 & 7 & 0 & \\
\hline None $^{a}$ & 7 & 24 & 5 & \\
\hline \multicolumn{5}{|l|}{ Type of intervention } \\
\hline $\begin{array}{l}\text { Drug/ } \\
\text { pharmacologic }\end{array}$ & 16 & 12 & 4 & 0.25 \\
\hline No treatment & 374 & 325 & 49 & \\
\hline \multicolumn{5}{|c|}{ Article mentioned adhering to reporting guidelines } \\
\hline Yes & 12 & 10 & 2 & 0.67 \\
\hline No & 378 & 327 & 51 & \\
\hline \multicolumn{5}{|l|}{ Article was funded } \\
\hline Yes & 94 & 79 & 15 & 0.49 \\
\hline No & 296 & 258 & 38 & \\
\hline \multicolumn{5}{|c|}{ Publishing journal requires AMA/ICMJE adherence } \\
\hline Yes & 137 & 118 & 19 & 0.99 \\
\hline No & 253 & 219 & 34 & \\
\hline
\end{tabular}

${ }_{\mathrm{a}}^{\mathrm{p}}$-Value calculated from Fisher's exact test.

adherence and article type, type of research, type of intervention, an article mentioning reporting guidelines, funding, or journals recommending AMAMS/ICMJE guidelines, nor journal impact factor (Table 2).

\section{Discussion}

The results of this study showed that articles focused on drug-seeking behavior often contain stigmatizing language as less than $15 \%$ of the articles included adhered to AMA guidelines. Information disseminated from medical professionals and researchers should use PFL by placing individuals before their diagnoses. PFL helps avoid labeling, and thus equating people with their disabilities or diseases, which is particularly important to patients with a substance dependency or addiction exhibiting drugseeking behaviors [8]. To our knowledge, this is the first study to examine the use of PFL as it pertains research focused on behavioral tendencies of addiction (i.e., drugseeking behaviors). A previous study of PFL adherence found that among scientific studies of alcohol use disorder, only 1 of 5 studies were adherent to PFL guidelines [25]. More recently, Ottwell et al. [26] found that $68 \%$ of publications focused on psoriasis did not adhere to PFL guidelines. Lastly, Barnish [27] found that the use of PFL in medical literature is becoming more prevalent as time progresses.

AMAMS guidelines [19] directly provide examples of terms - including addict, user, and abuser - to avoid when referring to patients with a substance use disorder or patients exhibiting drug-seeking behaviors. Our analysis found the terms "addict," "user," and "abuser" were used 128, 218, and 107 times, respectively. The National Alliance of Advocates for Buprenorphine Treatment suggests the use of "misuse" in place of "abuse" [28]. The rationale behind this recommendation is that the term misuse carries the same meaning as the term abuse, but does not carry the same stigma nor does it identify the patient by their disease.

Identifying a person by their condition - specifically a substance use disorder - may impact how physicians view their patients. One study comparing the use of PFL vs. a disease-first label to refer to a person with a substance use disorder found that clinicians "agreed more with the notion that the character [labeled as a 'substance abuser'] was personally culpable and that punitive measures should be taken” [29]. In contrast, research has shown that when providers positively use PFL, patients report higher levels of self-efficacy [30]. Given that over $85 \%$ of journal articles related to drug-seeking behavior contain non-PFL, significant improvements are still needed to both reduce stigma contained within medical literature.

\section{Recommendations for reducing stigma in scholarly writing}

Based on the results of our analysis - that only $13.4 \%$ of articles in our sample used PFL - and views previously expressed by Kameg [31], we recommend that all members of the scientific community become better acquainted with the core principles that motivate PFL. Although PFL 


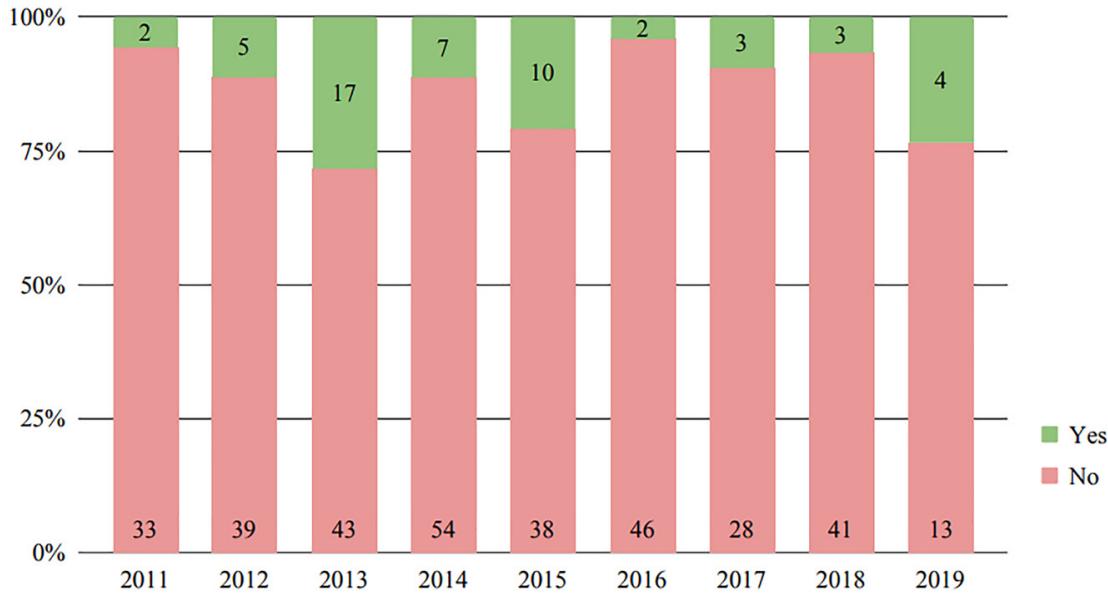

Figure 2: Percent of PFL adherent article focused on drug-seeking behavior by year.

Table 3: Non-person first language and frequencies over time.

\begin{tabular}{|c|c|c|c|c|c|c|c|c|c|c|}
\hline \multirow[t]{2}{*}{ Non-person first language terms } & \multicolumn{10}{|c|}{ Year } \\
\hline & 2011 & 2012 & 2013 & 2014 & 2015 & 2016 & 2017 & 2018 & 2019 & Total \\
\hline Drug seeker & 1 & 5 & 2 & 2 & 3 & 2 & 1 & 5 & 0 & $21(3.1 \%)$ \\
\hline Frequent flyer & 0 & 2 & 1 & 0 & 0 & 0 & 0 & 1 & 0 & $4(0.6 \%)$ \\
\hline Doctor shopper & 5 & 11 & 7 & 14 & 12 & 13 & 3 & 7 & 3 & $75(11.2 \%)$ \\
\hline Sufferer & 1 & 0 & 0 & 0 & 0 & 0 & 1 & 0 & 0 & $2(0.3 \%)$ \\
\hline Suffers from & 6 & 0 & 2 & 4 & 3 & 0 & 4 & 4 & 2 & $25(3.7 \%)$ \\
\hline Afflicted with & 0 & 2 & 1 & 1 & 0 & 1 & 1 & 0 & 0 & $6(0.9 \%)$ \\
\hline Problems with & 14 & 0 & 13 & 17 & 18 & 9 & 3 & 8 & 1 & 83 (12.4\%) \\
\hline Addict(s) & 18 & 15 & 20 & 22 & 12 & 14 & 12 & 11 & 4 & 128 (19.1\%) \\
\hline User(s) & 28 & 8 & 26 & 42 & 22 & 30 & 19 & 32 & 11 & 218 (32.6\%) \\
\hline Abuser(s) & 9 & 23 & 8 & 22 & 13 & 13 & 8 & 9 & 2 & 107 (16.0\%) \\
\hline Total & 82 & 66 & 80 & 124 & 83 & 82 & 52 & 77 & 23 & 669 \\
\hline
\end{tabular}

No instances of the terms "pill popper" or "pseudoaddict" occured. "User" includes the following terms: user, drug user, and substance user. "Abuser" includes the following terms: abuser, drug abuser, substance abuser, benzodiazepine abuser, and opioid abuser.

is taught in most health profession programs and mandated by scholarly journals, there remains a disconnect between what is demonstrated in publications, which may translate to clinical practice [8]. As multiple governing organizations call for the use of PFL, more guidelines are unlikely to solve the problem, as stigmatizing language is still found in articles published within journals with such requirements. Stricter screening by authors, editors, professional organizations, and scholarly journals may help mitigate non-PFL use. Finally, given the burden already placed on peer reviewers, an automated software program may be useful in evaluating articles for predetermined uses of non-PFL. Additionally, we suggest that the phrase "drug-seeking behavior" (a stigmatizing phrase rooted in provider perceptions) [32] be added to the list of non-PFL and that governing bodies advocate the removal of this phrase from both medical and scientific literature. In Table 4, we provide a list of commonly used non-PFL terms and phrases and appropriate alternatives that are less stigmatizing. Lastly, studies evaluating the consequences of using non-PFL in medical and scientific literature are warranted.

\section{Strengths and limitations}

Strengths of our study include the objectivity promoted by adopting predefined non-PFL examples directly from published guidelines, and that the extractors completed two days of training to classify these terms, which were extracted according to best practices. However, selecting these predefined terms is a limitation, as other non-PFL examples may have been missed. Another limitation is that previous journal submission guidelines were not available; thus, we could not control for when journals began to recommend adherence to AMAMS or ICMJE guidelines. Due 
Table 4: List of non-person first language terms and alternative choices.

\begin{tabular}{ll}
\hline Language to avoid & Acceptable alternatives \\
\hline $\begin{array}{l}\text { Frequent flyer } \\
\text { Doctor shopper }\end{array}$ & $\begin{array}{l}\text { Person who utilizes services and support } \\
\text { when necessary }\end{array}$ \\
$\begin{array}{l}\text { Addict } \\
\text { Abuser } \\
\text { User }\end{array}$ & $\begin{array}{l}\text { Person with substance use disorder } \\
\text { Pill popper } \\
\text { Drug seeker }\end{array}$ \\
$\begin{array}{l}\text { Suffering from } \\
\text { Afflicted with }\end{array}$ & $\begin{array}{l}\text { Experiencing } \\
\text { Living with }\end{array}$ \\
$\begin{array}{l}\text { Drug seeking } \\
\text { behavior }\end{array}$ & $\begin{array}{l}\text { Person attempting to attain a drug or drugs } \\
\text { Person with substance use disorder } \\
\text { attempting to obtain a controlled substance }\end{array}$ \\
Ex-addict & Person living in recovery \\
Recovered addict & Not actively using
\end{tabular}

List does not include all terms or phrases considered non-PFL.

to the cross-sectional design of this study and the specificity of our search string, our results may not be generalized to other disciplines.

\section{Conclusions}

Based on our findings, PFL adherence is rare within research publications focused on drug-seeking behavior. The power of language can be profound and should be understood by researchers, health care providers, and educators alike. We applaud the existing efforts to reduce stigma surrounding individuals with substance use disorders and encourage more efforts to be developed. We advocate for equal treatment of all patients and urge the use of PFL among scientific literature.

Research funding: None reported.

Author contributions: P.S., J.S., R.O., and M.V. provided substantial contributions to conception and design, acquisition of data, or analysis and interpretation of data; all authors drafted the article or revised it critically for important intellectual content; all authors gave final approval of the version of the article to be published; and all authors agree to be accountable for all aspects of the work in ensuring that questions related to the accuracy or integrity of any part of the work are appropriately investigated and resolved.

Competing interests: None reported.

\section{References}

1. National Institute on Drug Abuse. What is the scope of prescription drug misuse?; n.d. https://www.drugabuse.gov/ publications/ research-reports/misuse-prescription-drugs/what-scopeprescription-drug-misuse [accessed 4 May 2020].

2. Hedegaard H, Miniño AM, Warner M. Drug overdose deaths in the United States, 1999-2018. NCHS Data Brief 2020:1-8.

3. World Drug Report 2019; n.d. https://wdr.unodc.org/wdr2019/ [Accessed 25 Jun 2020].

4. Hansen GR. The drug-seeking patient in the emergency room. Emerg Med Clin North Am 2005;23:349-65.

5. Addressing Prescription Drug Abuse in the United States; n.d. https://www.cdc.gov/drugoverdose/pdf/hhs_prescription_ drug_abuse_report_09.2013.pdf [Accessed 25 Jun 2020].

6. Longo LP, Parran T Jr, Johnson B, Kinsey W. Addiction: part II. Identification and management of the drug-seeking patient. Am Fam Phys 2000;61:2401-8.

7. Collier R. Person-first language: what it means to be a "person". CMAJ 2012;184:E935-6.

8. Crocker AF, Smith SN. Person-first language: are we practicing what we preach? J Multidiscip Healthc 2019;12:125-9.

9. Pivovarova E, Stein MD. In their own words: language preferences of individuals who use heroin. Addiction 2019;114:1785-90.

10. Scholten W, Simon O, Maremmani I, Wells C, Kelly JF, Hämmig R, et al. Access to treatment with controlled medicines rationale and recommendations for neutral, precise, and respectful language. Publ Health 2017;153:147-53.

11. Broyles LM, Binswanger IA, Jenkins JA, Finnell DS, Faseru $B$, Cavaiola A, et al. Confronting inadvertent stigma and pejorative language in addiction scholarship: a recognition and response. Subst Abuse 2014;35:217-21.

12. Hammarlund RA, Crapanzano KA, Luce L, Mulligan LA, Ward KM. Review of the effects of self-stigma and perceived social stigma on the treatment-seeking decisions of individuals with drug- and alcohol-use disorders. Subst Abuse Rehabil 2018;9: 115-36.

13. Biancarelli DL, Biello KB, Childs E, Drainoni M, Salhaney P, Edeza $A$, et al. Strategies used by people who inject drugs to avoid stigma in healthcare settings. Drug Alcohol Depend 2019;198: 80-6.

14. American Psychological Association. Publication manual of the American Psychological Association. Washington, DC: American Psychological Association; 2019.

15. Guidelines for nonhandicapping language in APA Journals; $n$.d.

16. Committee AM of S, AMA Manual of Style Committee. AMA manual of style. AMA Manual of Style 2020. https://doi.org/10.1093/ jama/9780190246556.001.0001.

17. Network J, Network J, Alink M, Iverson C, Christiansen S, Flanagin A, et al. AMA manual of style: a guide for authors and editors. USA: Oxford University Press; 2007.

18. The Jama Network. AMA manual of style: a guide for authors and editors. USA: Oxford University Press; 2020.

19. AMA manual of style, 11th ed. USA: Oxford University Press; 2020.

20. ICMJE. Recommendations / Preparing a manuscript for Submission to a medical Journal n.d. http://www.icmje.org/ recommendations/browse/manuscript-preparation/preparingfor-submission.html [Accessed 28 May 2020]. 
21. Biernikiewicz M, Germain N, Toumi M. Second opinions, multiple physician appointments, and overlapping prescriptions in the paediatric population: a systematic literature review. J Eval Clin Pract 2020;26:1761-7.

22. Section 811; n.d. https://www.deadiversion.usdoj.gov/21cfr/ 21usc/811.htm [Accessed 23 May 2020].

23. Electronic Code of Federal Regulations. US Department of Health and Human Services' Code of Federal Regulation 45 CFR 46.102(d); n.d.

24. SAMHSA, Center for Behavioral Health Statistics. Quality. Section 2 PE Tables - Results from the 2018 National Survey on Drug Use and Health: Detailed Tables, Sections. SAMHSA, CBHSQ; n.d.:1-3 pp. https://www.samhsa.gov/data/sites/default/files/cbhsqreports/NSDUHDetailedTabs2018R2/

NSDUHDetTabsSect2pe2018.htm\#tab2-1b [Accessed 3 Apr 2020].

25. Hartwell M, Naberhaus B, Arnhart C, Ottwell R, Dunn K, Rogers TC, et al. The use of person-centered language in scientific research articles focusing on alcohol use disorder. Drug Alcohol Depend 2020;216:108209.

26. Ottwell R, Heigle B, Reddy AK, Sajjadi N, Wirtz A, Cook C, et al. The use of person-centered language in medical research journals focusing on psoriasis: cross-sectional analysis. JMIR Dermatology 2021;4:e28415.

27. Barnish M. A quantitative content analysis of person-first language use in healthcare research, healthcare practice, and by support groups for people with disabilities. OJML 2014;04: 505-11.

28. Drug Addiction and Buprenorphine. Treatment Glossary of Terms http://www.naabt.org/glossary.cfm [Accessed 14 Aug 2021].

29. Kelly JF, Westerhoff CM. Does it matter how we refer to individuals with substance-related conditions? A randomized study of two commonly used terms. Int J Drug Pol 2010;21:202-7.

30. Finney Rutten LJ, Hesse BW, St Sauver JL, Wilson P, Chawla N, Hartigan DB, et al. Health self-efficacy among populations with multiple chronic conditions: the value of patient-centered communication. Adv Ther 2016;33:1440-51.

31. Kameg BN. Shifting the paradigm for opioid use disorder: changing the language. J Nurse Pract 2019;15:757-9.

32. McCaffery M, Grimm MA, Pasero C, Ferrell B, Uman GC. On the meaning of "drug seeking". Pain Manag Nurs 2005;6: 122-36. 